\title{
Predicting the Uniaxial Compressive Response of Granular Media over a Wide Range of Strain Rates Using the Strain Energy Density Concept
}

\author{
Eduardo Suescun-Florez ${ }^{1} \cdot$ Sina Kashuk $^{1} \cdot$ Magued Iskander $^{1}\left(\mathbb{D} \cdot\right.$ Stephan Bless $^{1}$
}

Received: 23 March 2015/Accepted: 17 July 2015/Published online: 28 July 2015

(C) Society for Experimental Mechanics, Inc 2015

\begin{abstract}
An empirical non-linear method to predict stress-strain response of sand over a wide range of strain rates is presented. The method is inspired by the equivalence of the strain energy density (SED) of the material, at different strain rates. Silica based and calcium based sands were subjected to one-dimensional compression radially constrained tests to calibrate the methodology. Axial stress, axial strain and stiffness are also presented to assess the sensitivity of mechanical properties to strain rate. The observations show that sand under monotonic loading exhibits moderate strain rate dependency. This extent of rate varies with sand composition. There is good agreement between the strain rate behavior obtained from conventional tests and SED predictions derived from the proposed analysis.
\end{abstract}

Keywords Strain energy density $\cdot$ Strain rate $\cdot$ Sand . Particle crushing · Uniaxial compression

\section{Introduction}

The development of resilient civil infrastructure requires that structures not only be able to support the anticipated dead and live design loads, but also unanticipated transient loads. Many of these unexpected events are naturally created such as tornados, tsunamis, and earthquakes; or manmade, such as bomb blasts, collisions or industrial accidents. These transient loads generally affect and are

\footnotetext{
Magued Iskander

iskander@nyu.edu

1 Civil and Urban Engineering Department, New York University, New York, NY 11201, USA
}

affected by the surrounding soils. A common factor among many rapid loading scenarios is that they produce large strains in soils over a very short period of time, which is difficult to reproduce in conventional geotechnical laboratory tests. Thus, the ability to predict the strain rate dependency of soils is useful for predicting the response of infrastructure to high strain rate (HSR) loading effects.

Many protective structures are made of granular soils, including sands and silts. The effects of strain rate on the behavior of sand are also important for several types of loading that occur during engineering operations [1] including pile driving [2-4], ground improvement [5], in situ subsurface explorations [6,7], among others.

Several studies have investigated the role of strain rate on the behavior of sand. A recent review of HSR behavior of sand is available in Omidvar et al. [8]. The available research results appear inconsistent and some discrepancies are evident when results of tests conducted at low to intermediate strain rate regimes are compared. Early studies suggest that stiffness can vary by up to $10 \%$ depending on the rate of loading $[9,10]$, whereas others found that the strain rate dependency of the mechanical properties of sand is negligible [11, 12].

Models based on the work done along a stress-strain path have been employed to predict viscosity effects in materials [13]. One finding is that the stress-strain curve of many engineering materials at a desired strain rate can be obtained from a test conducted at a slower rate by applying the Strain Energy Density (SED) method. The starting point of this theory is based on an experiential argument that stresses are proportional to a power of the ratio of strain rates, at points having the same SED. The power is a material property. This method has been successfully utilized to predict creep of polymers such as high-density polyethylene (HDPE) [14, 15], low-density polyethylene 
(LDPE) [16], pavements [17], and cracking evolution in concrete [18].

This paper aims to evaluate the role of low to intermediate strain rate loading on granular media at uniaxial compression conditions. In addition, the goal is to validate a proposed empirical method inspired by the SED concept, comparing its results with those from the experimental program herein conducted.

\section{Experimental Program}

An experimental program was undertaken to investigate the effect of strain rate on the behavior of sand, and to validate the SED methodology discussed next. To guarantee consistent uniaxial compression results (a) the loading system must be capable of applying the required force in the time imposed by the applied load speed, (b) the applied stress along the specimen must be uniform, which is typically achieved by adopting a diameter to thickness ratio on the order of 6-10 [19], (c) boundary effects on the specimen, including side and end friction, should be minimized, and (d) complete radial constraint must be guaranteed.

\section{Sand Properties}

Two different naturally occurring sands were tested: silica sand and crushed coral sand. Silica sand distributed by US Silica under the commercial name \#1-dry was used. Particles are sub-rounded to subangular with medium to high sphericity having diameters ranging from 10 to $800 \mu \mathrm{m}$ (Fig. 1). The average particle size $\left(D_{50}\right)$ was found to be $340 \mu \mathrm{m}$ and coefficient of uniformity of 1.59 . The material is poorly graded and classified as SP according to ASTM's Unified Soil Classification System (USCS). Its maximum and minimum densities are 1.84 and $1.43 \mathrm{~g} / \mathrm{cm}^{3}$ according to ASTM D4253 [20] and ASTM 4254 [21] respectively, and the specific gravity was 2.66 .

The second sand was a Coral sand, purchased from an aquarium store, labeled with the commercial name Carib Sea. It was crushed in a grinder and separated into different grain size ranges. These particles are sub-rounded and less angular than those of the silica sand. Particles size varies from 10 to $1500 \mu \mathrm{m}$ exhibiting medium to high sphericity. The average particle size $\left(\mathrm{D}_{50}\right)$ was found to be $615 \mu \mathrm{m}$ and coefficient of uniformity of 1.92. The material is poorly graded and is classified as SP according to the USCS (Fig. 1). Its maximum and minimum densities are
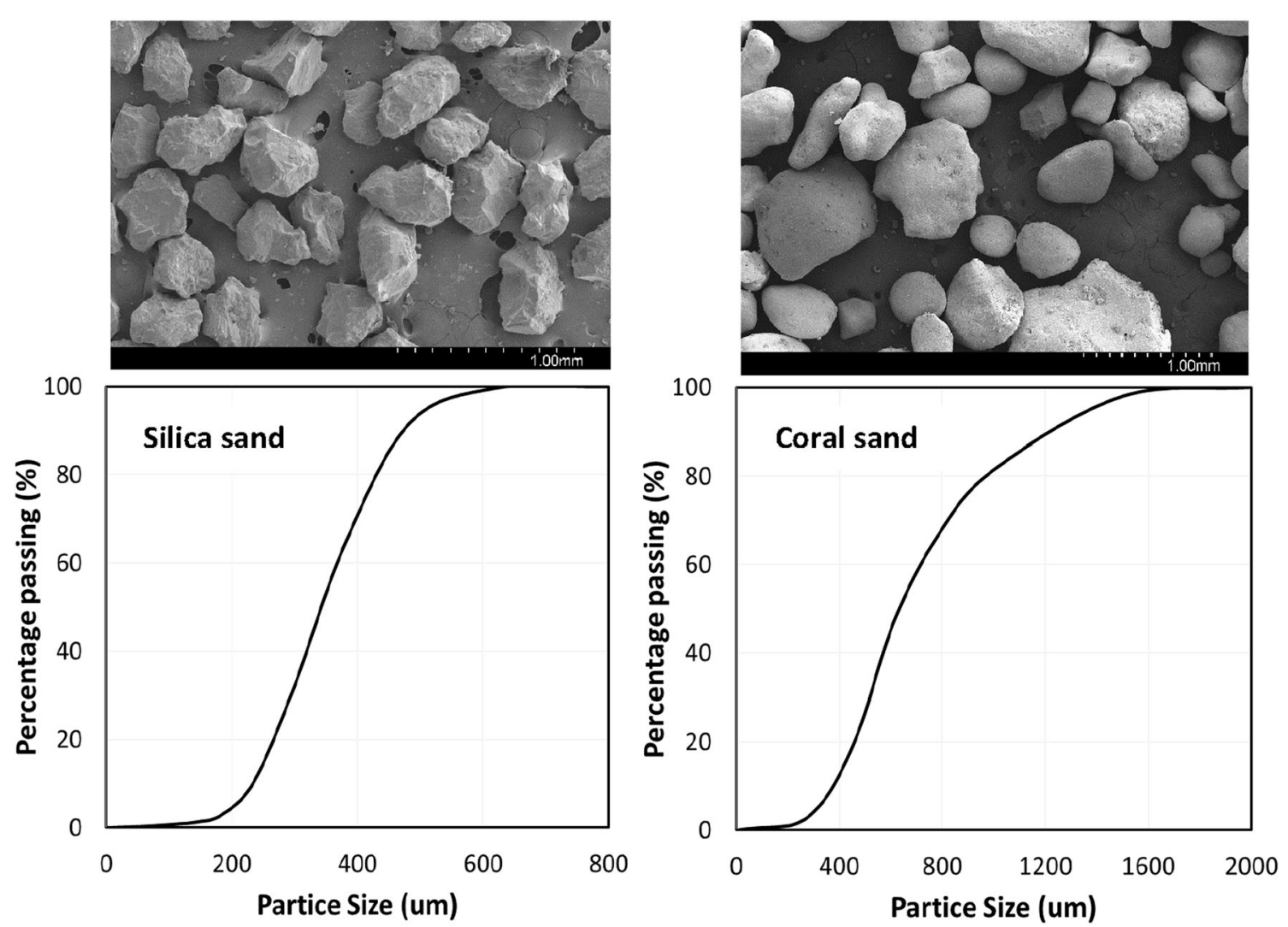

Fig. 1 Images of silica sand and coral sand samples used in this investigation, and particle size distribution for silica sand coral sands 
Table 1 Physical properties for the tested sand

\begin{tabular}{lll}
\hline Property & Silica sand & Coral sand \\
\hline Particle size analysis & & \\
Average diameter, $\mathrm{D}_{50}(\mu \mathrm{m})$ & 340 & 615 \\
Coefficient of uniformity, $\mathrm{Cu}$ & 1.59 & 1.92 \\
Coefficient of curvature, $\mathrm{Cc}$ & 1.00 & 1.11 \\
USCS classification & $\mathrm{SP}$ & $\mathrm{SP}$ \\
Specific gravity, Gs & 2.66 & 2.65 \\
Dry unit weights & & \\
Maximum, $\gamma \mathrm{d}_{\max }\left(\mathrm{g} / \mathrm{cm}^{3}\right)$ & 1.84 & 1.81 \\
Minimum, $\gamma \mathrm{d}_{\min }\left(\mathrm{g} / \mathrm{cm}^{3}\right)$ & 1.43 & 1.55 \\
Tested, $\gamma \mathrm{d}_{\text {test }}\left(\mathrm{g} / \mathrm{cm}^{3}\right)$ & 1.75 & 1.76 \\
\hline
\end{tabular}

1.81 and $1.55 \mathrm{~g} / \mathrm{cm}^{3}$ according to ASTM D4253 [20] and ASTM 4254 [21] respectively, with a specific gravity of 2.65. A summary of the physical properties of the test sands are shown in Table 1.

\section{Specimen Preparation and Test Mold}

Uniaxial compression tests were conducted on dry samples having a diameter and thickness of 76.2 and $12.7 \mathrm{~mm}$, respectively. Samples were symmetrical in shape and prepared at a relative density of $75 \%$ in a stainless steel mold that assured full restraint of radial deformations. The mold weighed $7.50 \mathrm{~kg}$, which assured sufficient stability when rapid loads are applied (Fig. 2). Dry sand mass was carefully poured into the mold using a spoon and vibrated for approximately $10 \mathrm{~min}$ to a predetermined height to achieve the desired uniform density. Sample dimensions and weights were validated to ensure consistent relative densities and initial void ratios. Finally, samples were covered by a rigid stainless steel cap, having a diameter and height of 76.2 and $38.1 \mathrm{~mm}$, respectively.

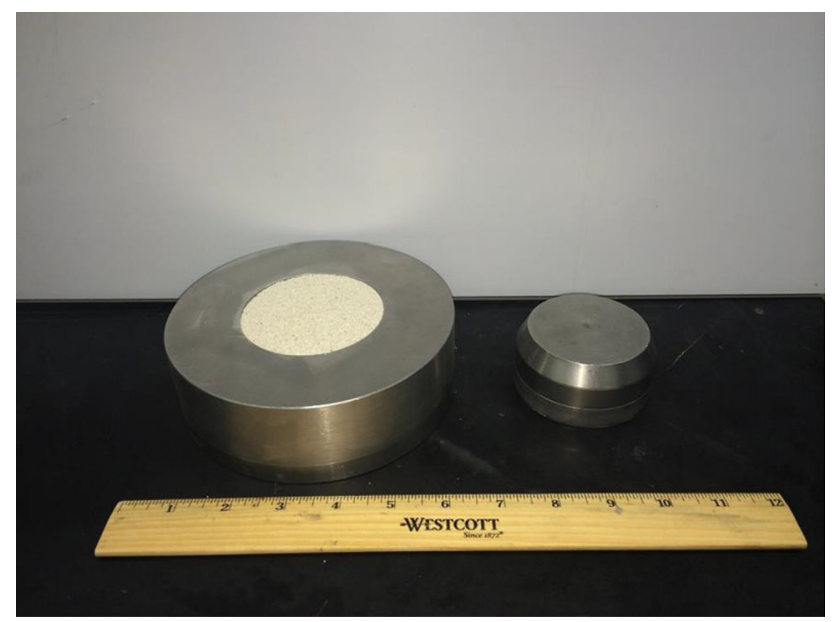

Fig. 2 Stainless steel chamber used for uniaxial compression tests

\section{Hydraulic Loading System}

Uniaxial compression tests were performed at different strain rates using a two-column load frame equipped with a MTS hydraulic actuator having 110kip force capacity. The hydraulic actuator is operated by an Instron digital controller. A seating stress of $10 \mathrm{kPa}$ was applied onto the sample, to ensure that the strain is applied at a uniform rate. The strain reported due to the seating stress application is later on removed in all experiment' results. These values are considered negligible compared to the stress levels the specimen can withhold. The hydraulic actuator is in contact with the stainless steel cap, which is in direct contact with the sand sample. Stress, strain, and time were recorded for every test performed. The time dependent behavior of these sands was observed when samples were loaded at four strain rates including $0.01,0.1,1$, and $10 \% / \mathrm{s}$ corresponding to test durations of $2500,250,25$, and $2.5 \mathrm{~s}$ respectively. Engineering stresses and strain are used throughout this paper with no area correction, since the diameter was assured constant.

\section{Data Conditioning}

Values of time, stress, and strain for any two different strain rates are transferred from the data acquisition unit of the hydraulic load testing system to the computer. Since the test time varies from one strain rate to another, different sampling rates were employed to acquire the data of each test. As a result, a standard discrete strain space was defined for all experiments' results to facilitate further calculations. Initially, three to four tests of each identical condition were performed to verify the reliability of the test results. Next, averages of identical conditions were constructed. The compliance effects of the loading frame can influence the measured displacements. To minimize these effects, all tests were conducted on a single test frame using identical base fixture, load plates, and stainless steel chamber. In any case, the stiffness and resistance of all fixtures, frame, and chamber were significantly higher than the tested granular materials.

\section{Experimental Results}

\section{Tests Repeatability}

Tests were carried out to 15-25\% strain and they are shown in Fig. 3 for silica sand, and Fig. 4 for coral sand. These strain values where chosen because they are considered well beyond the tolerable strain range in civil engineering applications. Experimental tests are plotted in thin dashed lines whereas averages are shown in thick solid 


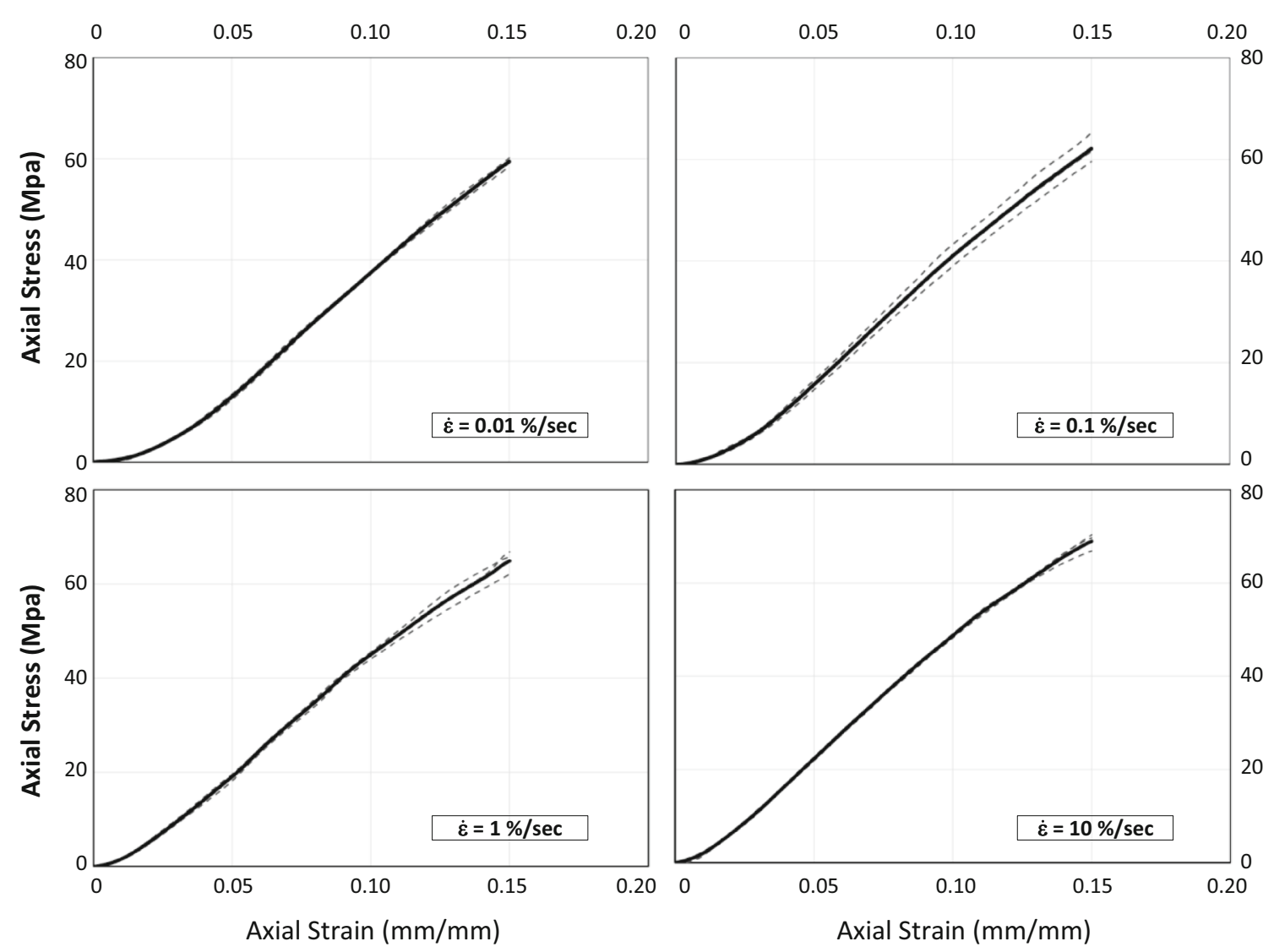

Fig. 3 Stress-strain curves of uniaxial compression tests on silica sand at different strain rates (experimental tests are shown as thin dashed lines and average is shown as a thick solid line)

lines. For any strain rate, both sands exhibit little variability in its stress-strain response, particularly at strain below $5 \%$.

Although the variation is not significant along the tests, coral sand exhibits somewhat more scatter in the 5-25\% strain range, probably due to the following reasons: (1) there is lower hardness and resistance to crushing of coral particles relative to those of silica sand, and (2) particle sizes of coral sand are larger than those of silica sand. The combination of these two factors can promote particle damage somewhat faster in coral than in silica sand, which is manifested in small variations of the stress-strain response for each test. However, from the number of tests performed at different strain rates it can be see that results are sufficiently repeatable to justify the use of the average of actual test results, which will be utilized for analysis.

\section{Effect of Strain Rate on Stiffness}

Averages of the stress-strain response at different strain rates for silica sand and coral sand were constructed to facilitate the analysis of the role of the strain rate on the mechanical response of these materials. Tests with strain rates varying by up to four orders of magnitude from 0.01 to $10 \% / \mathrm{s}$ are illustrated in Fig. 5 for silica and coral sands. From these figures several observations can be gleaned.

First, Silica sand exhibits a stiffer response than coral sand. For instance, at $10 \%$ strain the axial stress in silica sand is in the range of $37-50 \mathrm{MPa}$, whereas in coral sand stresses are only 10-25 MPa.

Second, both silica and coral sands exhibit stiffer respond as the strain rate increases; however, the rate of strength increase depends on the material composition. Silica sand exhibits about $15 \%$ of stress increase when the strain rate varied from the slowest to the highest. This value can be compared with that of coral sand in which the role of strain rate induces an increase of up to $36 \%$ in stress. This effect can also be observed when the constrained modulus, taken between 5 and $15 \%$ is computed (Fig. 6). Constrained modulus is defined as the slope of the stress-strain curve of a fully radially constrained soil sample, which inhibits volumetric dilation. As a result, although silica sand is initially stiffer and stronger than coral sand, the stiffness increase rate is slightly larger in the calcium-based material. 

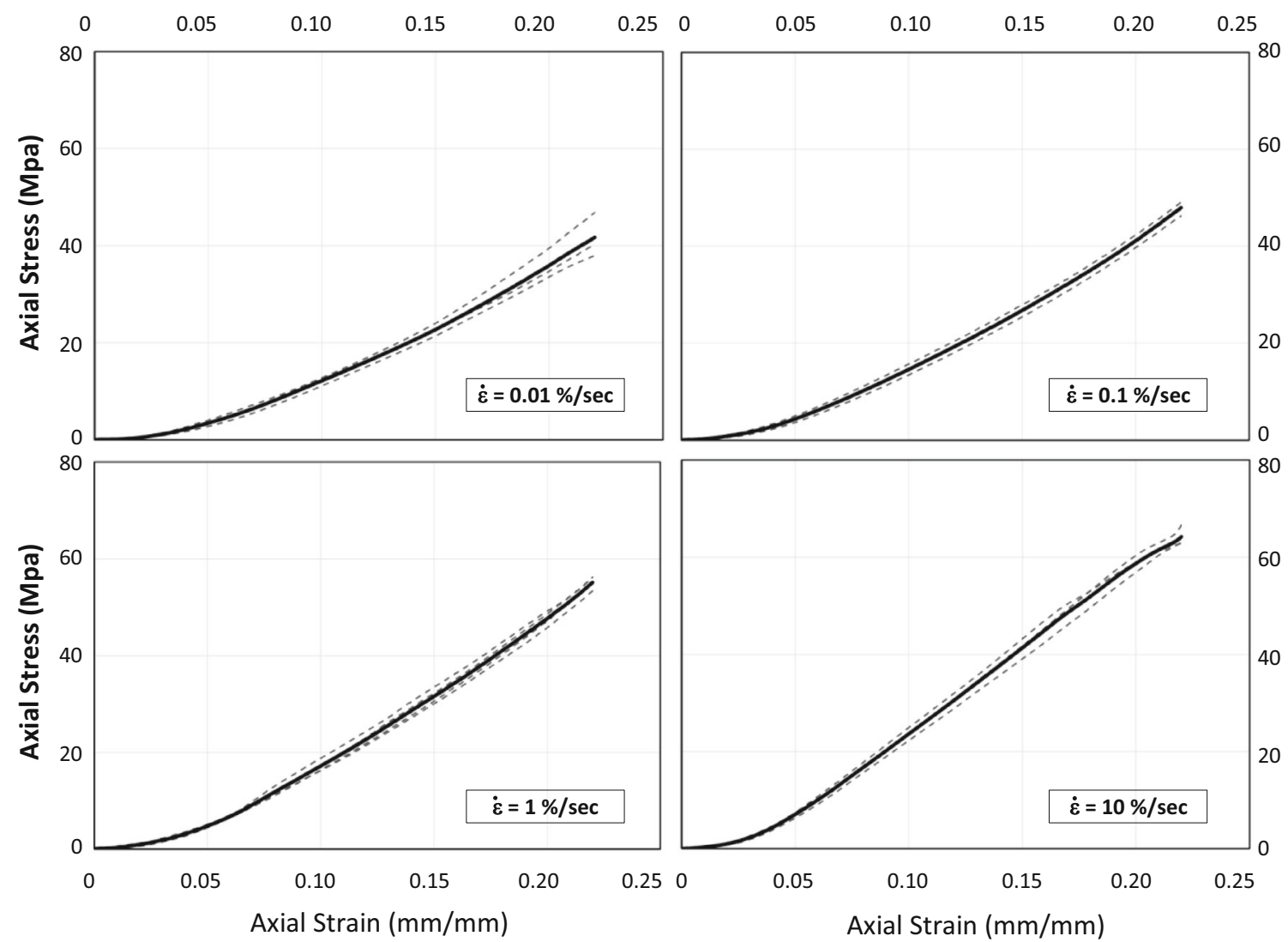

Fig. 4 Stress-strain curves of uniaxial compression tests on coral sand at different strain rates (experimental tests are shown as thin dashed lines and average is shown as a thick solid line)
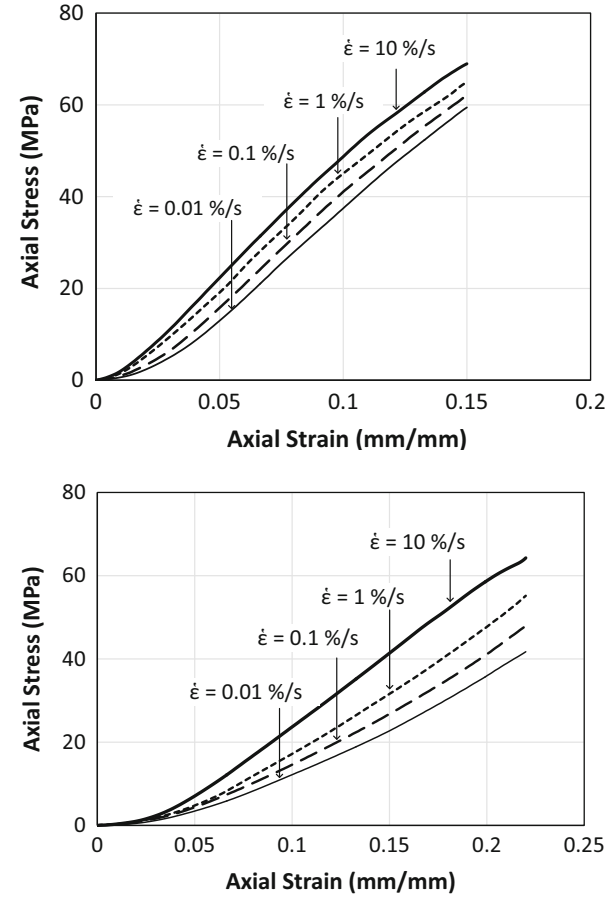

Fig. 5 Average stress-strain curves of silica sand (top) and coral sand (bottom) loaded in uniaxial compression at shown strain rates

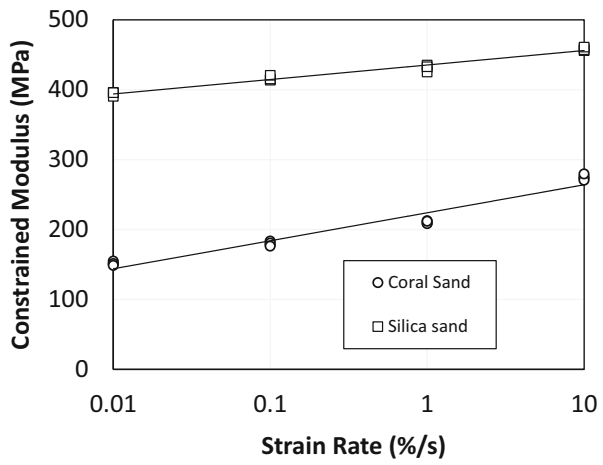

Fig. 6 Effect of strain rate on the constrained modulus of silica and coral sand (constrained modulus defined over a strain range from 5 to $15 \%)$

Third, the initial portion of the stress-strain curves is concave up and shows an inflexion point at about 1 and $2 \%$ in silica and coral sands respectively. The stress-strain curves become steeper after the initial concave effect and more linear up till the end of the test. The initial curvature may be attributed to two different mechanisms: (a) seating errors discussed in ASTM D695, and it is more noticeable in coral sand due to its weaker composition; and/or 
(b) variable compliance of the loading frame, since compliance may have a greater effect at low stresses.

Finally, the effects of strain rate are difficult to identify in the initial $5 \%$ of strain, and the effect starts appearing earlier in silica sand than in coral sand. At the early stages of loading static and intermediate strain rate tests exhibit similar stiffness. The small difference in initial tangents may be attributed to minor differences on actual densities of test samples and/or minor differences in seating and application of contact stresses. At $0.5 \%$ strain, curves start exhibiting different stiffness and higher strain rate tests depict stiffer response, since test time is reduced and soil grains are less likely to rearrange compared to slower tests. At higher stress levels, less particle breakage occurs under HSR loading compared to static monotonic loading, since particle crushing is a time-consuming phenomenon [8]. The result is a stiffer response in faster events.

\section{Stress Uniformity and Inertial Effects}

The method by which the load is applied to the specimen plays a significant role in the mechanical response of these sands. The use of a specific loading mechanism and its accurate response to variation of strain rate need to be corroborated to validate the outcomes from the loading system. A review on HSR testing techniques, and issues related to inertial effects on granular behavior can be found in Suescun et al. [22]. In this work, testing low to intermediate strain rates on different sands includes the observation of the load rise time, which relates the time duration that the hydraulic system takes to reach the maximum stress, and not an intrinsic behavior of the sand column. Since the experiments described herein were performed at different load velocities their load rise times are also different. A comparison of axial stress with test time for all strain rates applied (Fig. 7) indicates that the load rise time curves are parallel. The horizontal axis of the figure is in

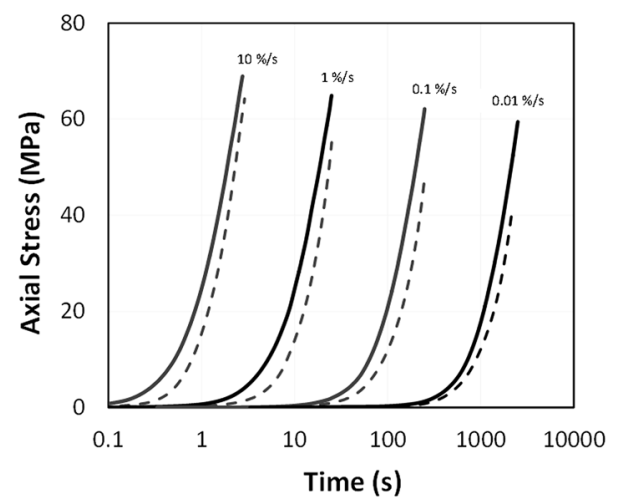

Fig. 7 Loading rise time for silica sand (solid lines) and coral sand (dashed lines) at several strain rates logarithmic scale leading to the observation that higher strain rate tests reach stress equilibrium faster than low strain rates. Furthermore, it was found that the loading rise time is inversely proportional to the strain rate, and the slope of the load-time curve becomes steeper as the strain rate increases.

As the soil specimen is accelerated from its initial static state to the dynamic state, additional resistance beyond the static axial stress is experienced by the sample due to inertial forces associated with the mass of the soil in the specimen and the top-cap. The inertial force directly opposes the applied force from the hydraulic load. The vertical inertial force in the specimen is greatest at the top of the specimen because that is where the change in velocity is the greatest. The vertical inertia force reduces to zero at the base of the specimen because this location maintains zero acceleration throughout the test. Considering full radial restraint, the specimen does not experience radial inertial forces. From Fig. 7 it is also observed that after a very brief period of acceleration, the measured global axial stress exhibit a nearly linear character with test time indicating a constant loading velocity. Thus, the only portion of the stress-strain behavior affected by inertia is, for the fastest tests $(10$ and $1 \% / \mathrm{s})$, at the very start of the test (up to $5 \%$ of strain). Thus, most of the test can be considered free from inertial effects.

Verification that the strain rate could be taken as constant was conducted by calculation of the velocity of the piston at each sampling point (Fig. 8). This verification is very useful for evaluating models of rate dependent behavior. The engineering strain rate is then the velocity divided by the initial sample height. One of the main challenges in HSR testing is to achieve stress and strain rate uniformity. Uniformity is easier to achieve in low to intermediate strain rates regimes, than in HSR regimes.

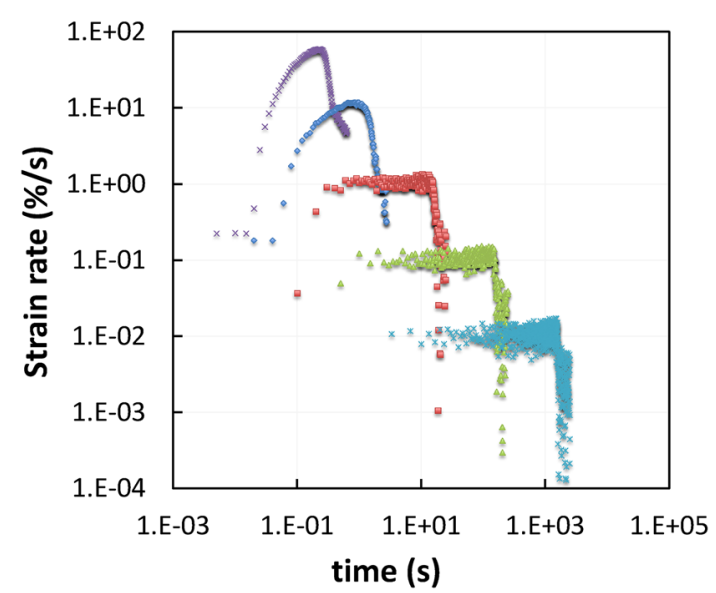

Fig. 8 Sustained strain rate values during uniaxial compression tests. As the targeted strain rate increases the time where the strain rate is uniform becomes smaller 
Nevertheless, a sustained regime of strain rate is necessary for use of global measurements of stress and strain in the analysis. Figure 8 shows where the strain rate is indeed constant during the time the load is applied. Among several strain rates tested the nominal highest value, $100 \% / \mathrm{s}$ value did not achieve steadiness. The peak strain rate achieved barely reached $50 \% / \mathrm{s}$. Those results were not included in our analysis because they do not represent a constant rate of deformation.

\section{Particle Damage}

Particle damage occurs when the stress exceeds particle strength. It is evidently a function of strain rate. Under quasi-static loading, particle breakage is related to (1) confining stresses, (2) porosity, (3) particle shape, (4) mineralogy, (5) size distribution, and (6) presence of flaws within the micro-structure of the grains. Higher pressures and lower porosities inhibit shear-induced dilation thus promoting particle damage [23]. In transient events, particle damage is also affected by level of sustained load, and time of sustained load. When damage in the soil particles occurs, a new particle size distribution within the specimen is generated, and the quantification of damage is desired so careful measurements are needed.

Grain size distribution, sphericity, and shape factors were assessed using a particle size analyzer, which is commercially named as QicPic ${ }^{\mathrm{TM}}$ from Sympatec ${ }^{\mathrm{TM}}$. Particles are fed through a hopper into a venturi where they are dispersed using compressed air. Particle shapes are captured using a high-speed camera at a resolution of four Megapixels. Edges are precisely detected when the particle flow is imaged in transmission using a special objective lens transmitting light rays to the camera that are parallel to the optical axis.

Particle size distribution of silica and coral sands loaded at different strain rates is shown in Fig. 9. The figures illustrate the role of the strain rate on crushing of sand
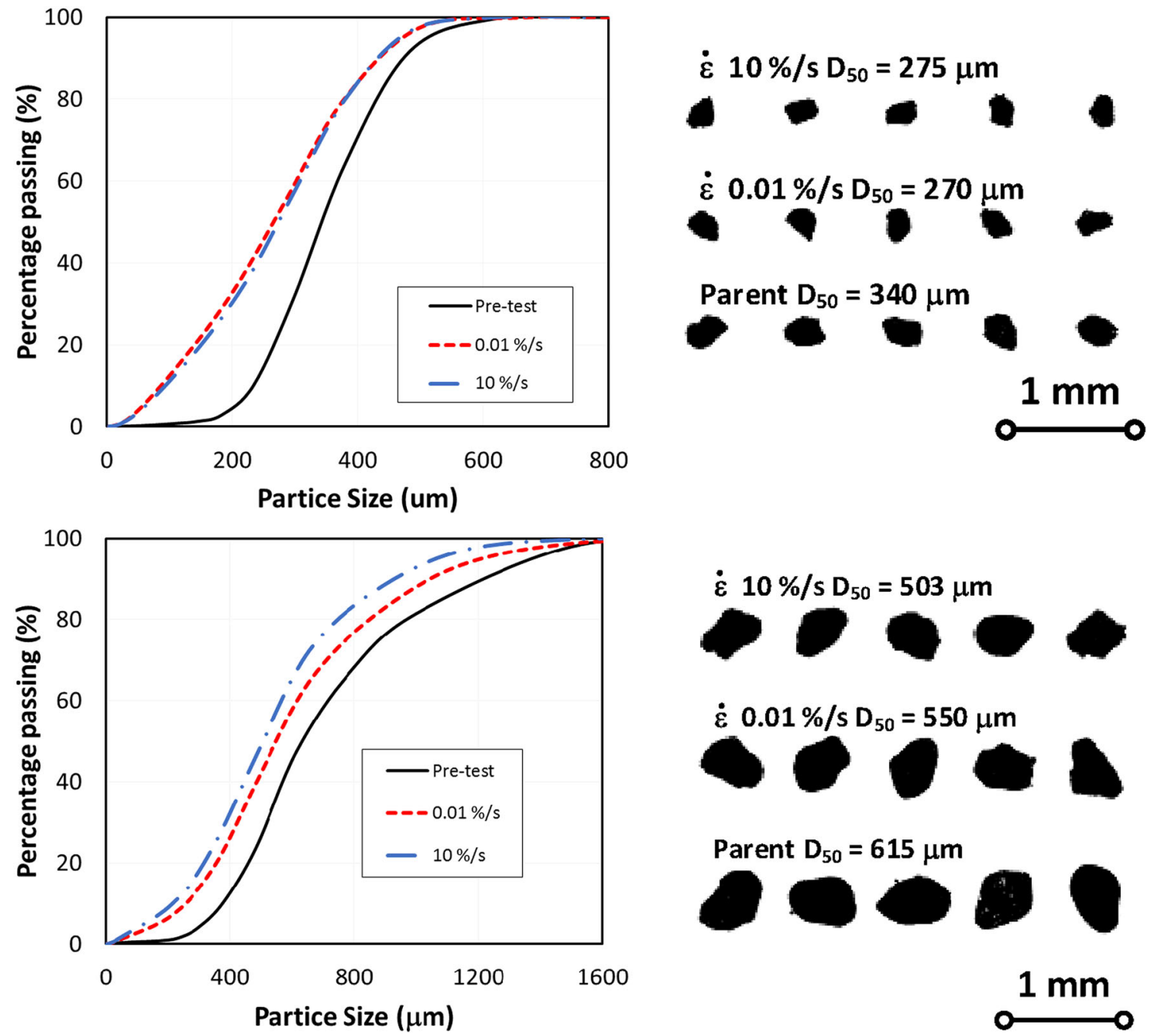

Fig. 9 Evolution of particle size distribution due to strain rate variations in silica sand (top) and coral sand (bottom) 
particles. All loading conditions resulted in particle breakage. Nonetheless, the damage of silica and coral sands is somewhat different when strain rate dependency is considered. Particle breakage is found to be a crucial mechanism involved in the mechanical behavior of sands besides others mechanisms (i.e., friction and packing). They together contribute to the rate dependency behavior of sands [24]. Test duration and test stage induce the development of one or more mechanisms at the same time. In coral sand, once the particle resistance has been reached, grains exhibit a clear strain rate effect because new particle size distributions are generated as strain rate changes. Moreover, there is an identified trend of size reduction as strain rate loading increases. On the other hand, silica sand response does not show an obvious trend. Particles crush leading to the evolution of daughter particles that remain similar in shape and size regardless strain rate variations.

The quantification of particle breakage in sand subjected to HSR has been studied for decades; however, still inconsistencies among the observations remain. Perhaps the loading mechanics in which the breakage is induced plays a significant role on quantifying breakage. Some studies $[25,26]$ demonstrated, testing one dimensional and triaxial compression conditions respectively, that in transient loading particles have less time to break, giving rise the conclusion that the damage level was more significant when loading rate was low. On the other hand, the influence of loading rate on particle breakage was also demonstrated by Kabir et al. [27] by comparing HSR triaxial tests using the Split Hopkinson Pressure Bar (SHPB) and quasi-static hydraulic tests. They observed that although failure and particle crushing were eventually reached in both loading conditions, the damage level is more significant when strain rates increases.

Aspect ratio and sphericity parameters were utilized to characterize the shape of particles. The effect of the strain rate on the aspect ratio of particles is shown for both sands in Fig. 10. Aspect ratio is defined as the ratio of the largest to the smallest diameters that are orthogonal to each other. It can be seen that particles of silica and coral sands possess aspect ratios ranging from 0.6 to 0.75 on the entire size spectrum. It can also be seen for both sands that values do not dramatically change when strain rate changes. However, particle sizes of silica sand larger than $500 \mu \mathrm{m}$ tend to evolve into smaller particles with higher aspect ratio. A similar, but less evident, effect can also be seen for coral sand.

The variation of sphericity with strain rate loading is illustrated in Fig. 11. Sphericity is defined as the ratio of the perimeter of the equivalent circle to the total perimeter. Sphericity values varies from 0 to 1 ; small values indicate a more irregular shape, whereas high values specify more
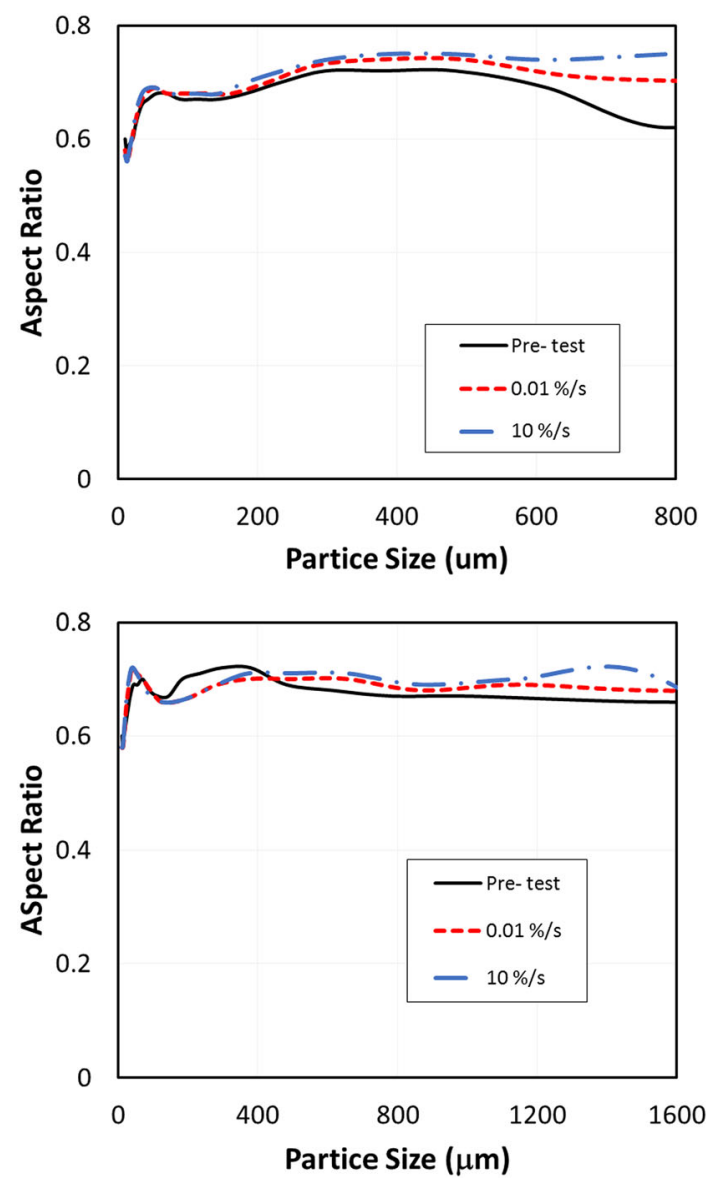

Fig. 10 Evolution of the aspect ratio for silica sand (top) and coral sand (bottom)

uniform particles. The effect of the loading rate on change in sphericity of daughter particles is found to be negligible.

\section{Modeling the Effect of Strain Rate on the Behavior of Sand}

\section{Phenomenology}

The mechanical behavior of sand at quasi-static and HSR exhibits different responses. In quasi-static uniaxial compression tests, one usually observes initial stiff behavior, followed by softening, then hardening; this behavior is usually explained by initial elastic compression of individual sand particles, followed by slippage and rearrangement of particles promoting a denser packing. If the load is further increased and/or sustained, particle crushing may take place depending on the stress level that grains can sustain.

When HSR is applied, sand particles move and flow during the test. New mechanisms can be perceived which 

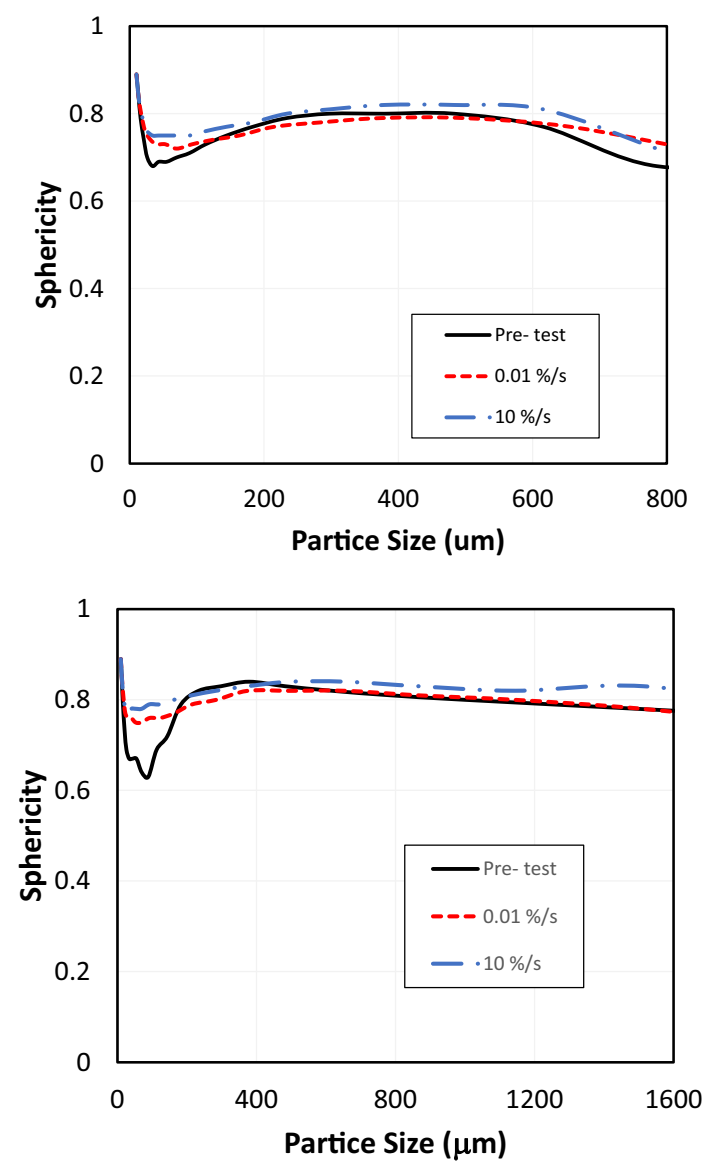

Fig. 11 Evolution of sphericity for silica sand (top) and coral sand (bottom)

include (a) inertia forces opposing the loading stress thus facilitating stress wave propagation, (b) stress wave propagation occurring from one end of the sample to the other, (c) a stress uniformity is eventually reached when many propagations superimpose over one another, (d) a rapid particle rearrangement is observed, and (e) particle crushing can also be observed if grain resistance is reached. Since HSR involves transient loads a dynamic cyclic condition is not likely to happen. However, if particle crushing is observed, a new particle size distribution can be expected. In general, HSR behavior may arise because all strain mechanisms except grain elasticity require movement of particles, which may be truncated by insufficient load duration.

The form of the stress-strain curves resembles classic viscoplastic behavior with a relatively rate dependent response. Many constitutive formulations have been suggested: (a) the Perzyna's theory [28], the most well-known formulation, where viscous behavior is modeled with a time-rate flow rule, and (b) the Duvant-Lions theory [29, 30], in which the viscous behavior is fabricated based on the difference between solutions for non-viscous and viscoplastic formulations. Other constitutive models related to rate dependency have been developed based on the aforementioned formulations including the three-phase equation-of-state (EOS) [31-33]. EOS soil models take into account the different compressibilities of the solid, water and air phases of soil.

In this study another simple model to predict the strain rate dependency of sand is explored. The model assumes SED equivalency between a given stress-strain test and another one conducted at a higher strain rate. The equivalence is assumed to incorporate the effects of visco-elasticity and visco-plasticity through the use of an exponential relationship defined in the next section.

\section{Equivalent Strain Energy Density (SED) Method}

The energy stored in a body due to deformation is called the strain energy, and the strain energy per unit volume is called the SED. When there is only one non-zero principle strain, the SED can be identified as the area underneath the stress-strain curve up to the point of deformation of interest. In this work, the SED concept is applied to stressstrain curves of sand from one dimensional (1-D) compression and the macro-scale response is analyzed. The nature of the macro-scale analysis excludes lateral deformation occurring within the soil. This approach does not account for particle and meso scale degrees of freedom permitting multi-axial strains such as friction, rotation, and translation of particles that takes place to accommodate axial strain.

The concept of the SED theory has been applied to study the instability of materials [34]. The theory is based on the hypothesis that a continuum element comprised of an assembly of small elements, each one containing a unit volume, can only store a finite amount of energy at any given time.

In general, the SED, $W$, of a material is defined as the strain energy, $U$, per volume, $V$. It is equal to the area under the stress-strain diagram of a material, measured from $\varepsilon_{\mathrm{x}}=0$ to $\varepsilon_{\mathrm{x}}=\varepsilon_{1}$ as follows

$W=\frac{U}{V}=\int_{0}^{\varepsilon_{1}} \sigma_{x} \times \mathrm{d} \varepsilon_{x}$

where $\sigma_{x}$ and $\varepsilon_{x}$ are the stress and strain components at a given point.

The SED concept hypothesizes that stress is proportional to a power, $m$, of the strain rates. For 1-D loading, in which the modulus of elasticity, $E$, is equal to the product of $\sigma$ and $1 / \varepsilon$, and for which the modulus is constant, a relationship between strain rates, stresses, and strain can be presented in the following equation:

$\left(\frac{\dot{\varepsilon}_{2}}{\dot{\varepsilon}_{1}}\right)^{m}=\frac{\sigma_{2}}{\sigma_{1}}=\frac{\varepsilon_{1}}{\varepsilon_{2}}$ 
where subscripts 1 and 2 are any two states, representing tests conducted at different strain rates. Thus any point on a stress-strain curve has a corresponding point on a different stress-strain curve conducted at a different strain rate so that the two points have the same energy density and satisfy Eq. (2) [13]. In that case, the SED theory resembles many dislocation-based models in which the flow stress is proportional to a power of the strain rate. It can be observed from the Eq. (2) that small values of $m$ imply a low time-dependent behavior.

When a particular material exhibits a viscoelastic behavior, and the stress-strain relation is linear, the SED hypothesis can be graphically understood as shown in Fig. 12. By equaling areas $A_{1}$ and $A_{2}$ the following relationship can be expressed as:

$\frac{E_{r 1} \times \varepsilon_{r 1}^{2}}{2}=\frac{E_{r 2} \times \varepsilon_{r 2}^{2}}{2}$

$\left(\frac{\sigma_{\mathrm{r} 2}}{\varepsilon_{\mathrm{r} 1}}\right)^{2}=\frac{E_{\mathrm{r} 1}}{E_{\mathrm{r} 2}}$

$\frac{\varepsilon_{\mathrm{r} 2}}{\varepsilon_{\mathrm{r} 1}}=\sqrt{\frac{E_{\mathrm{r} 1}}{E_{\mathrm{r} 2}}}$

The availability of two stress-strain tests on the same material at different constant strain rates allows the prediction of a third stress-strain curve at any other strain rate. The first two tests are used to define $m$. Once $m$ is known, the third stress strain curve can be obtained by using one of the other two stress strain tests as a reference. Rearranging Eqs. (2) and (5), the $m$ value can be found as,

$\left(\frac{\dot{\varepsilon}_{r 1}}{\dot{\varepsilon}_{r 2}}\right)^{m}=\sqrt{\frac{E_{r 1}}{E_{r 2}}} \therefore m=\frac{\log \left(E_{r 1} / E_{r 2}\right)}{2 \log \left(\dot{\varepsilon}_{r 1} / \dot{\varepsilon}_{r 2}\right)}$

Assuming that $E$ changes with the rate of loading, but remains a constant for any particular strain rate, the term $m$ would also be a constant number that no longer depends on the SED. The value of $m$ converges to a constant value of 0.048 and 0.027 , for virgin and recycled HDPE, respectively, when tests with at least a difference of 2 or more orders of magnitude in their strain rates are used [35, 36].

\section{SED Applied to Modeling Stress-Strain Behavior of Granular Media}

A non-linear model inspired by the SED concept is proposed in this paper. Contrary to the viscoelastic linear behavior exhibited by HDPE, the mechanical response of granular media is highly nonlinear, and time and material composition dependent. Yielding stresses occur gradually with a steady transition from linear to nonlinear response under uniaxial compression as shown in Fig. 13 for full radial confinement. Granular materials exhibit a viscoelastic-viscoplastic response even at small loading ranges, which makes it difficult to identify where yielding starts. However, viscoelasticity is the fundamental assumption employed in SED. For this reason, the conventional SED method for viscoelastic materials, which employs a linear relationship and therefore a constant value of $m$ is unsuitable for characterizing rate effects in sand. Nevertheless, Suleiman and Coree [37] established that a linear model could be used to represent creep of viscoplastic materials. Thus a viscoelastic model may be used to approximate the behavior of viscoplastic materials, particularly if unloading or strain-reversal is not encountered in the problem being examined.

In the conventional SED method, a linear fit is commonly applied to the strain-stress curves to find the modulus of elasticity and calculate the SED as the area of a triangle, which is also the area under the stress-strain curve $[15,36]$. The proposed model, on the other hand, accounts
Fig. 12 Linear stress-strain behavior of visco-elastic materials with equal strain energy density (area $1=$ area 2 ; $\left.\dot{\varepsilon}_{1}>\dot{\varepsilon}_{2}\right)$
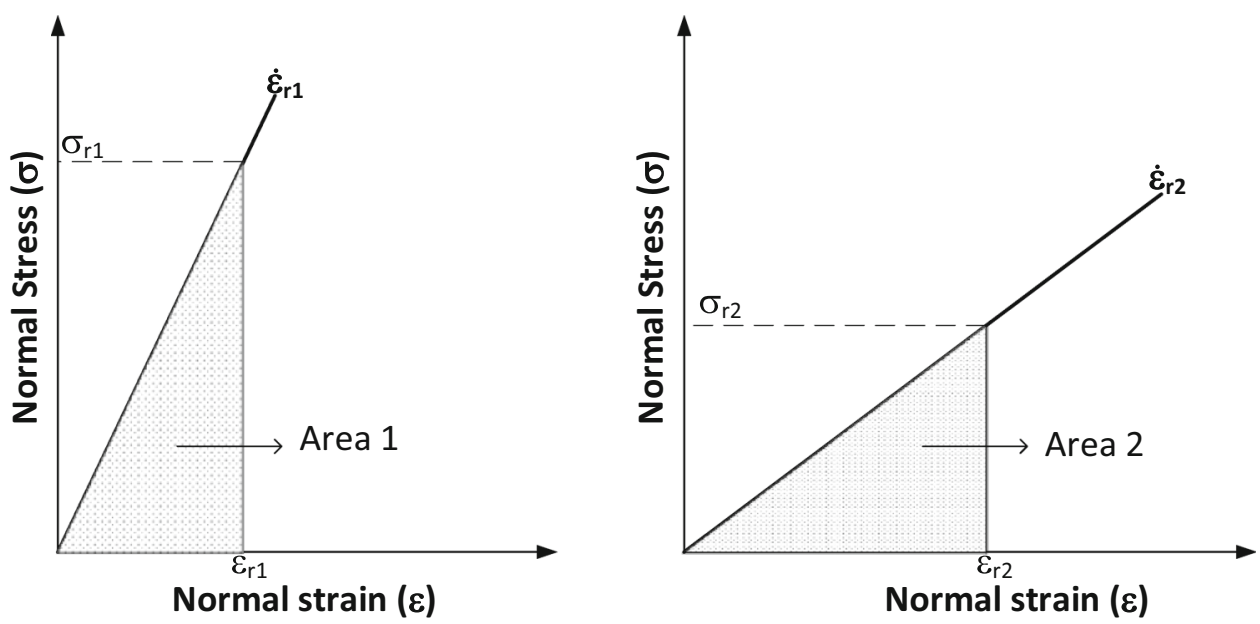


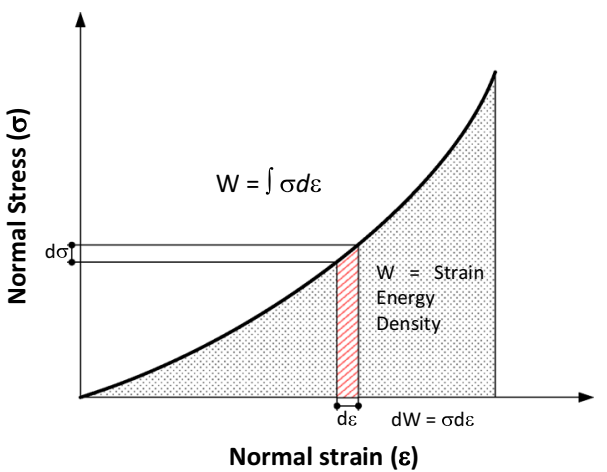

Fig. 13 Strain energy density concept for fully confined uniaxial compression tests

for the viscoplasticity of sand by applying a stepped viscoelastic model piece-meal, such that each portion of the stress-strain curve has a different value of $m$. The relationship for $m$ can be generalized by letting $m$ changes as SED changes. As a result values of $m$ are incremental and are a function of the strain level at any specific point of analysis (Fig. 13). Thus a spline function was employed, instead of the linear fit, to represent the stress-strain response. A spline is a numerical function that is piecewise-defined by polynomial functions, which possess a sufficiently high degree of smoothness at the places where the polynomial pieces connect. The proposed approach is believed to account for both viscoelastic and viscoplastic components of the behavior of sand.

A similar approach was proposed by Luo et al. [38] in quartz sand subjected to HSR loading via the SHPB. Unlike the use of strain rate variables, they found that the stress-strain relationship followed a power law relationship with the sand initial bulk density, indicating a behavior highly sensitive to mass density. They also related the energy absorption density and compressibility of sand with the axial stress.

\section{Limitations of the Proposed SED Approach}

The original SED method is based on Hooke's law where the energy stored in a loading is assumed proportional to the Young's elastic modulus. However, the stress-strain behavior of sand is far from being linear. In addition to the elastic response, in granular media other mechanisms such as particle rearrangement, and particle damage, also take place. Thus, the following limitations must be considered when applying the current method:

(1) Variation of the modulus with strain has long been recognized in soil mechanics [39]. The proposed approach presumes that variation of $E$ with strain can be extrapolated from one strain rate to another by employing SED principles.
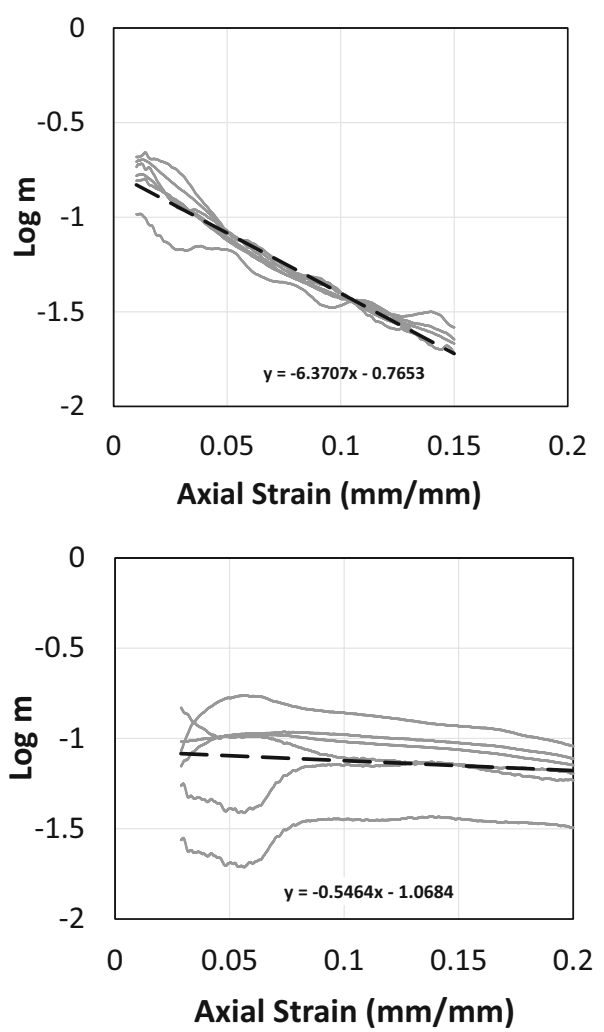

Fig. 14 Logarithmic values of $m$ showing the best fit linear trend for silica sand (top), and coral sand (bottom)

(2) The material's response becomes increasingly nonlinear at higher strain ranges, making the original linear SED equations increasingly invalid. Despite this limitation, the proposed SED inspired method captures the non-linear response as strain increases by adopting a piecewise definition of for viscoelastic behavior that accounts for all modes of soft matter deformation including elasticity, rearrangement, and damage.

(3) It may be possible that at some strain ranges, the stress-strain response of the sand is governed by one or more mechanisms. The current approach does not have the capabilities to identify the partial contribution of each mechanism but rather it applies the method by treating all mechanisms as a whole.

(4) Although E is a material property, its value in soils always falls within a well-known range of stiffness.

Table 2 Best fit power regression constants for $m$ values

\begin{tabular}{llll}
\hline$m=10^{(a \varepsilon+b)}$ & & & \\
\hline Silica sand & & Coral sand & \\
\hline $\mathrm{a}$ & $\mathrm{b}$ & $\mathrm{a}$ & $\mathrm{b}$ \\
-6.371 & -0.7653 & -0.5464 & -1.0684 \\
\hline
\end{tabular}


These variations can be attributed to small uncertainties due to particle composition, heterogeneity, and discrete media. The current SED approach employs slight variation of $\mathrm{E}$ as function of the strain.

The following steps describe the use of the Modified SED method in the granular soils of low to intermediate strain rates:

\section{Finding Log (m) Values for Different Reference Strain Rate Pairs}

An initial attempt to calculate $m$ as a rate dependent parameter for granular materials was done by modifying Eq. (6), when $\varepsilon_{1}$ and $\varepsilon_{2}$ are equal, as follows

$\log m(i)=\log \left(\frac{\log \left(\frac{\sigma_{1}}{\sigma_{2}}\right)}{\log \left(\frac{\dot{r}_{r 1}}{\dot{\varepsilon}_{r_{2}}}\right)}\right)$

Equation 7 permits smoothing and linearizing the relationship between $m$ and its corresponding strains. In this equation, $m$ is a power law exponent, which is the target coefficient related to any given pair of reference tests; $i$ is SED at any desired strain; $\dot{\varepsilon}_{r 1}$ and $\dot{\varepsilon}_{r 2}$ are the strain rates for the two initial reference tests ( 1 and 2); and $\sigma_{1}$ and $\sigma_{2}$ are the axial stress values corresponding to the reference curves 1 and 2 respectively. Since four strain rates were employed to test the methodology $(0.01,0.1,1$, and $10 \% /$ $\mathrm{s})$, the number of possible combinations to calculate the value of $m$ is six. Thus, six different $\log m$-strain scenarios were computed following Eq. (7), in order to explore the repeatability of this trend, and examine the sensitivity of $\log m$ to strain.

\section{$m$ Value as a Strain Rate Dependent Function}

The relationship between $\log m$ and strain was observed by plotting the six curves for each sand, and finding the best linear fit (Fig. 14). Although Eq. (7) is not explicitly a function of strain, each reference and predicted stress values correspond to its strain pair. As a result, the best linear fit from Fig. 14 can be expressed as follows:

$\log m=a(\varepsilon)+b$

where $a$ and $b$ can be identified as material constants since these values vary from one material to another. The variation of $a$ and $b$ could be attributed to other intrinsic variables of the material such as particle size distribution, angularity and roundness, particle flaws, among others. However, the practical current approach assumes a general variation that is material dependent. Thus, $m$ becomes a power function that depends on the axial strain and on two constants shown as follows,

$m=10^{(a \varepsilon+b)}$

As a result a relationship between $m$ and axial strain is established so $m$ is no longer constant as previously employed for materials with linear behavior.

\section{Predicted Stresses at Higher Strain Rates}

By rearranging Eqs. (2) and (9) the predicted stress $\sigma_{3}$ at any desired strain rate can be calculated as the following

$\sigma_{3}=\sigma_{1}\left(\frac{\dot{\varepsilon}_{2}}{\dot{\varepsilon}_{1}}\right)^{10^{(a+b)}}$

Finally, the predicted higher strain rate scenarios can be shown and compared to the experimental results.

\section{Prediction of Experimental Observations Using SED}

The current SED-inspired method can be applied to predict the stress-strain behavior of the tested silica and coral sands as follows. First, three to four tests on the same material, prepared at the same density, and loaded at the same strain rate are performed in order to compute their average stress-strain rate response, which is used for further calculations. Second, two stress-strain curves of different strain rates are chosen to define the double Logarithmic function of $m$ using Eq. (7). The calculation is repeated at every $0.01 \%$ strain such that the 2 corresponding stresses $\sigma_{1}, \sigma_{2}$ are obtained and a different value of $\log m$ is computed for each strain level. Third, a linear fit for the $\log m$ versus strain is obtained, in which fixed parameters $a$ and $b$ are found (Table 2). Finally, the predicted stress for the imaginary test at a higher strain rate $\left(\sigma_{3}\right)$ is obtained from the reference stress strain test conducted at a slower strain rate using Eq. (10), and substituting the values of $a$ and $b$ as well the strain rates for each point on the reference test. An example of finding predicted stresses in silica sand at $100 \% / \mathrm{s}$ of strain rate, based on two references stress-strain tests at 1 and $10 \% / \mathrm{s}$, is presented in Table 3.

In order to assess the model's capabilities, a set of stress-strain predictions up to $10 \% / \mathrm{s}$ was computed. The $m$ functions, for both silica and coral sands, were found based on the average values of Fig. 5. $m$ values were computed for the entire strain range of 0-20\%. Following the step-by-step process, the Log of $m$ was calculated as a function of the strain (Fig. 14). It is clear that Log of $m$ converges to a linear trend, which varies from one material to another. Silica sand and coral sand appear different when Log of $m$ is calculated. The Log of $m$ of 
Table 3 Representative calculation of stress-strain response at different strain rate using SED method

\begin{tabular}{|c|c|c|c|c|c|c|}
\hline \multirow{3}{*}{$\begin{array}{l}\text { Material } \\
\text { Strain } \\
\text { rate }\end{array}$} & \multicolumn{6}{|l|}{ Silica sand } \\
\hline & \multicolumn{6}{|c|}{1 And $10 \% / \mathrm{s}$ (reference tests) } \\
\hline & \multicolumn{6}{|c|}{$100 \% / \mathrm{s}$ (Predicted) } \\
\hline Strain & $\begin{array}{l}\sigma_{1} \dot{\varepsilon}_{r 1}=1 \% / \mathrm{s} \\
\quad(\mathrm{MPa})\end{array}$ & $\begin{array}{l}\sigma_{2} \dot{\varepsilon}_{r 1}=10 \% / \mathrm{s} \\
\quad(\mathrm{MPa})\end{array}$ & $\begin{array}{l}\log m \\
\text { (i) Eq. (7) }\end{array}$ & $\begin{array}{l}\text { Log } m \text { best fit } \\
\text { Eq. }(8)\end{array}$ & $\begin{array}{l}\mathrm{m} \\
\text { Eq. (9) }\end{array}$ & $\begin{array}{l}\sigma_{3}(100 \% / \mathrm{s} \text { predicted })(\mathrm{MPa}) \\
\text { Eq. }(10)\end{array}$ \\
\hline 0 & 0.000 & 0.000 & -0.828 & -0.765 & 0.172 & 0.000 \\
\hline 0.01 & 1.575 & 2.000 & -0.984 & -0.829 & 0.148 & 2.813 \\
\hline 0.02 & 5.146 & 6.190 & -1.096 & -0.893 & 0.128 & 8.308 \\
\hline 0.03 & 9.514 & 11.121 & -1.169 & -0.956 & 0.111 & 14.336 \\
\hline 0.04 & 14.227 & 16.687 & -1.159 & -1.020 & 0.095 & 20.776 \\
\hline 0.05 & 19.095 & 22.302 & -1.171 & -1.084 & 0.082 & 26.945 \\
\hline 0.06 & 24.685 & 27.899 & -1.274 & -1.148 & 0.071 & 32.844 \\
\hline 0.07 & 29.975 & 33.323 & -1.337 & -1.211 & 0.061 & 38.361 \\
\hline 0.08 & 35.005 & 38.706 & -1.360 & -1.275 & 0.053 & 43.705 \\
\hline 0.09 & 40.426 & 43.858 & -1.451 & -1.339 & 0.046 & 48.705 \\
\hline 0.1 & 45.029 & 48.709 & -1.467 & -1.402 & 0.040 & 53.320 \\
\hline 0.11 & 49.245 & 53.545 & -1.439 & -1.466 & 0.034 & 57.891 \\
\hline 0.12 & 53.525 & 57.605 & -1.496 & -1.530 & 0.030 & 61.618 \\
\hline 0.13 & 57.524 & 61.660 & -1.521 & -1.593 & 0.025 & 65.349 \\
\hline 0.14 & 61.045 & 65.660 & -1.500 & -1.657 & 0.022 & 69.036 \\
\hline 0.15 & 64.920 & 68.954 & -1.582 & -1.721 & 0.019 & 72.003 \\
\hline
\end{tabular}

silica sand is more sensitive to the axial strain than that of coral sand, although values of silica sand exhibit less scatter than those of coral sand. As a result, the bestfit logarithmic functions were identified using Eq. (8).

The variation of $m$ with strain is illustrated in Fig. 15. It is noteworthy that $m$ changes significantly from one material to another. The value of $m$ for coral sand slightly varies in the strain domain whereas $m$ for silica sand reveals a concave behavior in which the highest deviation is shown at the first $10 \%$ of deformation.

The $m$ function for each sand is then replaced in Eq. (10) to predict the stress, using another test as a reference test. Since the stress levels, and the exponential function of $m$ differ from silica sand to coral sand, the predicted stress values for both sands are also different. Averages of the actual experiments are plotted together along with the stress-strain curves predicted using the SED inspired method, as shown in Figs. 16 and 17 for silica sand and coral sand, respectively. The stress strain curves predicted by the SED techniques agree with measured curves generally within the repeatability of experimental data.

The variation of the stress-strain response with the order of magnitude for strain rate pairs is also illustrated in Figs. 16 and 17 for silica sand and coral sand respectively. In silica sand, this effect is negligible. Each plot of Fig. 16a-c includes five thin solid black lines corresponding to strain rate pairs. The solid lines basically overlap, which makes it difficult to identify differences. On the other hand, coral sand provides a somewhat different response. When pairs involving stress-strain tests with rates differing by two and three orders of magnitude are used the scatter in the predicted stress-strain is significantly reduced, whereas the scatter increases as the order of magnitude reduces. These results are consistent with Bozorg-Haddad and Iskander [35, 36] for virgin and recycled plastics respectively.

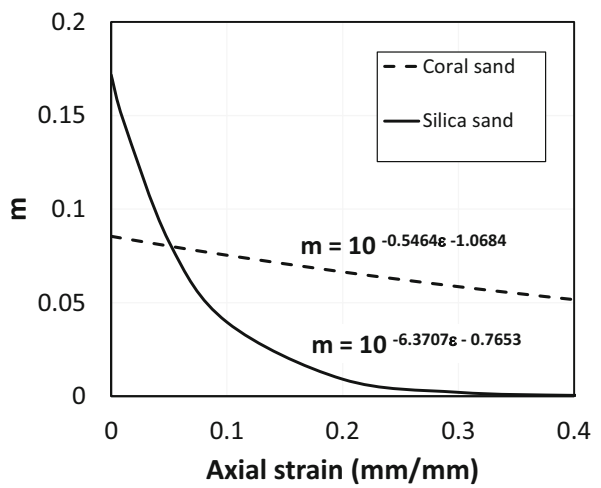

Fig. $15 m$ values as function of vertical strain for silica sand and coral sand 

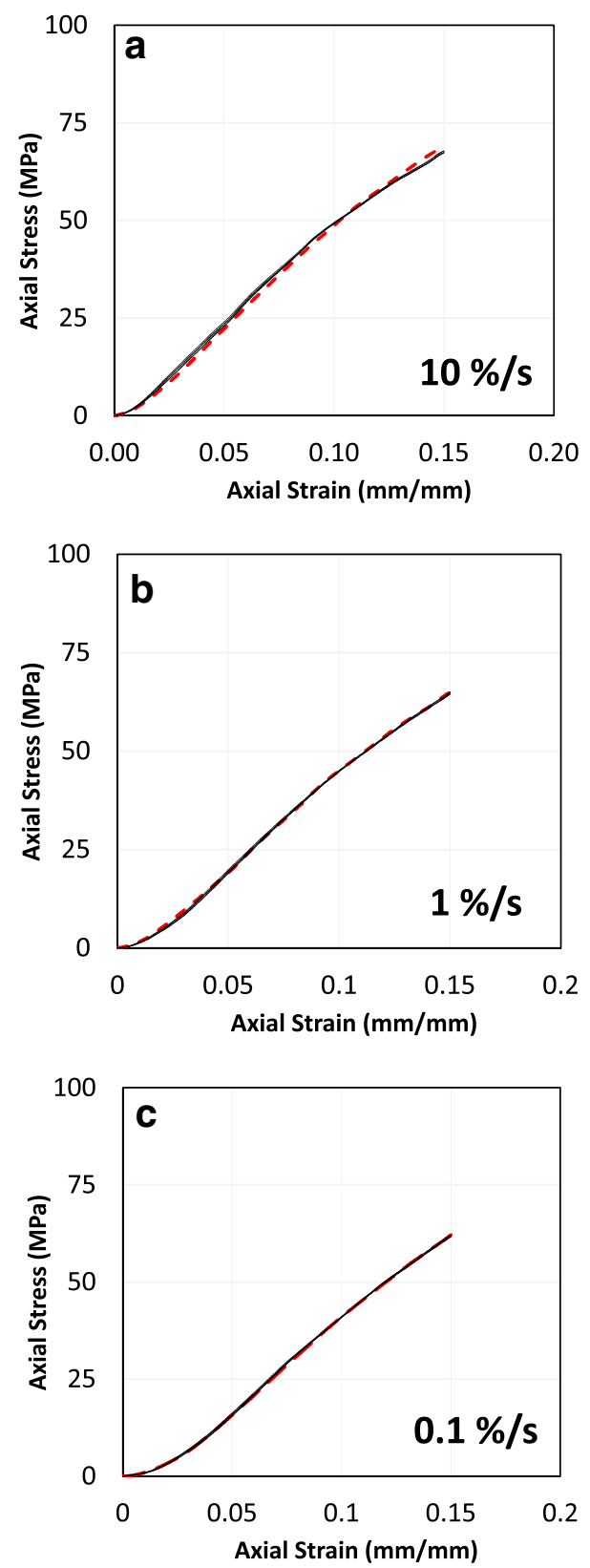

Fig. 16 Experimental versus predicted stress-strain curves on silica sand. Each figure also illustrates the effect of variation of strain rate pairs for the analysis. Experimental data are shown in dashed lines, and predicted data in solid lines

\section{Extrapolation of Results to HSR Loading}

Stress-strain curves of HSR loading were also extrapolated from the available data. Strain rates of 100, 1000, 10,000, and $50,000 \% / \mathrm{s}$ were computed using the SED inspired approach for silica and coral sands. Predictions were performed using the experimental data for the 0.01 and $10 \% / \mathrm{s}$ strain rate range. In order to validate the extrapolated results, a new set of experiments was carried out to
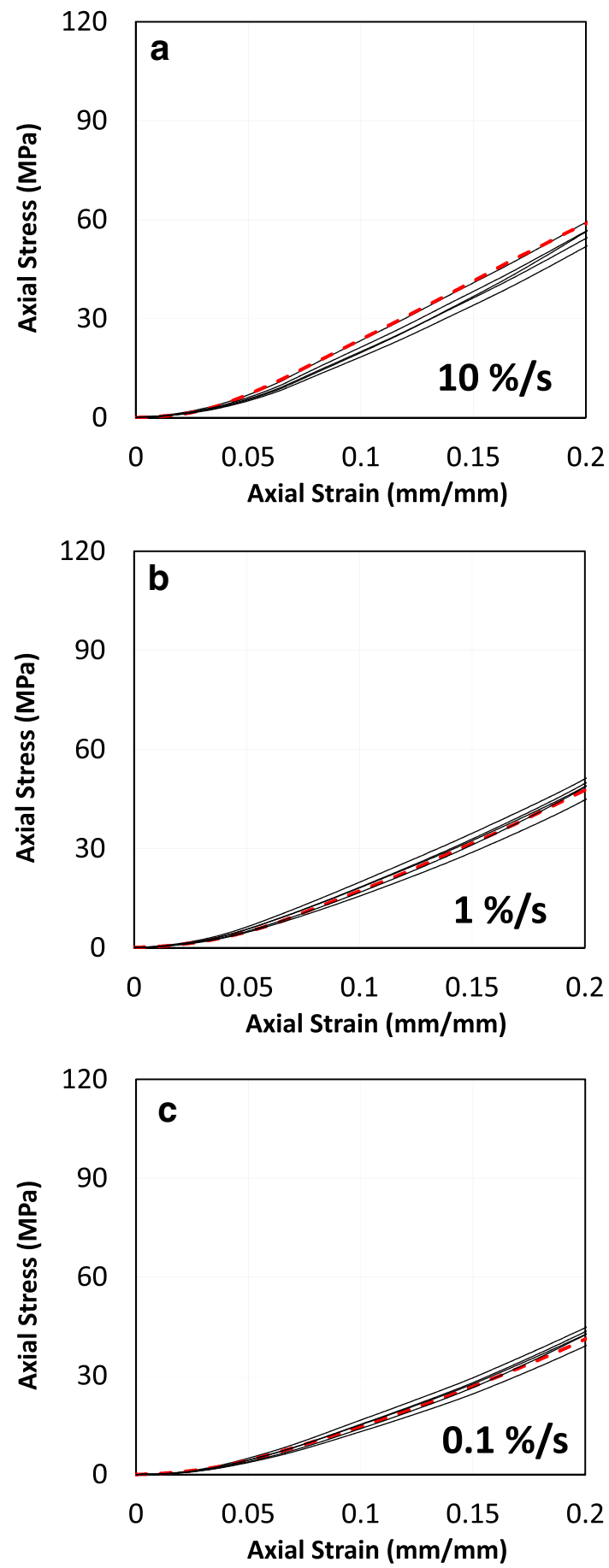

Fig. 17 Experimental versus predicted stress-strain curves on coral sand. Each figure also illustrates the effect of variation of strain rate pairs for the analysis. Experimental data are shown in dashed lines, and predicted data in solid lines

compare with the SED predictions. Due to the mechanical limitation of the hydraulic frame utilized initially, a dropweight tower was employed to drop weights of about $13.5 \mathrm{~kg}$ at heights varying from 0.10 to $1.6 \mathrm{~m}$ in order to achieve the desired strain rates. The target specimens were 

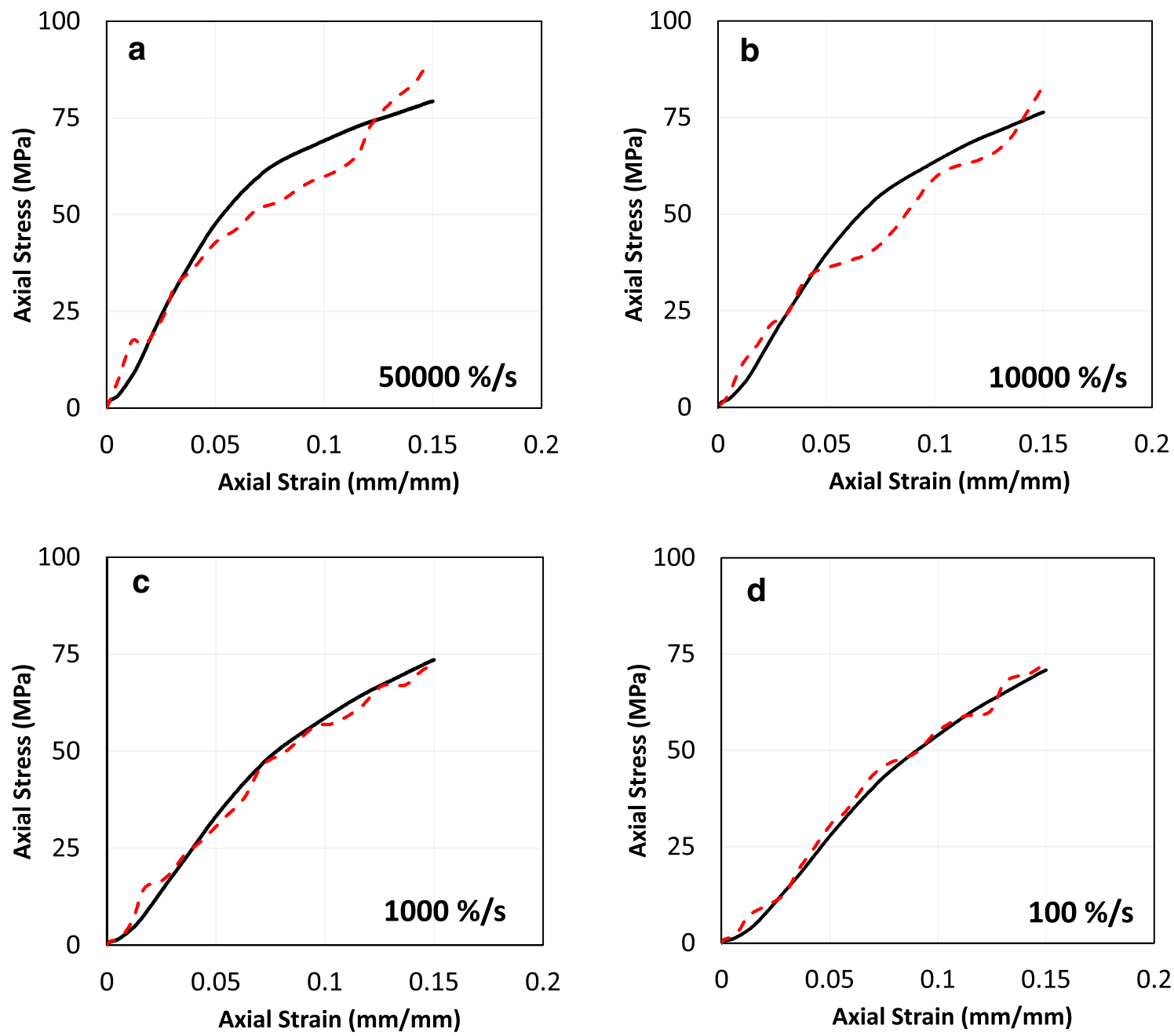

Fig. 18 HSR experimental versus predicted stress-strain curves of a 500,000\%/s, b 10,000\%/s, c $1000 \% / \mathrm{s}$, and d $100 \% / \mathrm{s}$ in silica sand (experimental data is shown in dashed lines, and predicted data in solid lines)

$12.5 \mathrm{~mm}$ in diameter and height to allow for higher impact stresses, than would be possible with the original $76.2 \mathrm{~mm}$ in diameter specimen. Samples were placed in the same stainless steel uniaxial chamber used on previous tests. This was accomplished by inserting a sleeve, $76.2 \mathrm{~mm}$ in external diameter and $12.50 \mathrm{~mm}$ in internal diameter in the chamber to encase the small specimens. Similar relative densities of about $85 \%$ were employed using mechanical vibration and tamping.

The results of experimental versus predicted curves are plotted in Fig. 18 for silica and Fig. 19 for coral sand. It can be seen that as the strain rate increases the two compared curves become less compatible. In addition, tests conducted at strain rates higher than $100 \% / \mathrm{s}$, especially in silica sand, exhibit some differences at the earlier stages of strain. These discrepancies can be attributed to a combination of factors including (1) difference in loading systems resulting in different load types (impact versus rapid), (2) impact loading, causing some bouncing and load reversals, and (3) higher stresses caused by the impact probably resulting in particle crushing, which introduces new mechanisms not accounted for by the SED. Nevertheless, the measured and predicted responses are reasonably close, particularly for engineering purposes.

In light of the comparison, several observations can be drawn: first, the current method provides a very useful engineering approach for interpolation or modest extrapolation of available data. Second, this approach was more accurate when loading did not introduce new phenomena that are not captured by the experimental data collected at lower strain rates.

\section{Conclusions}

A series of uniaxial compression tests was conducted to evaluate the dependency of the mechanical behavior of two natural granular materials: silica and coral sands on strain rate. Loading rise time for both samples were compared to 

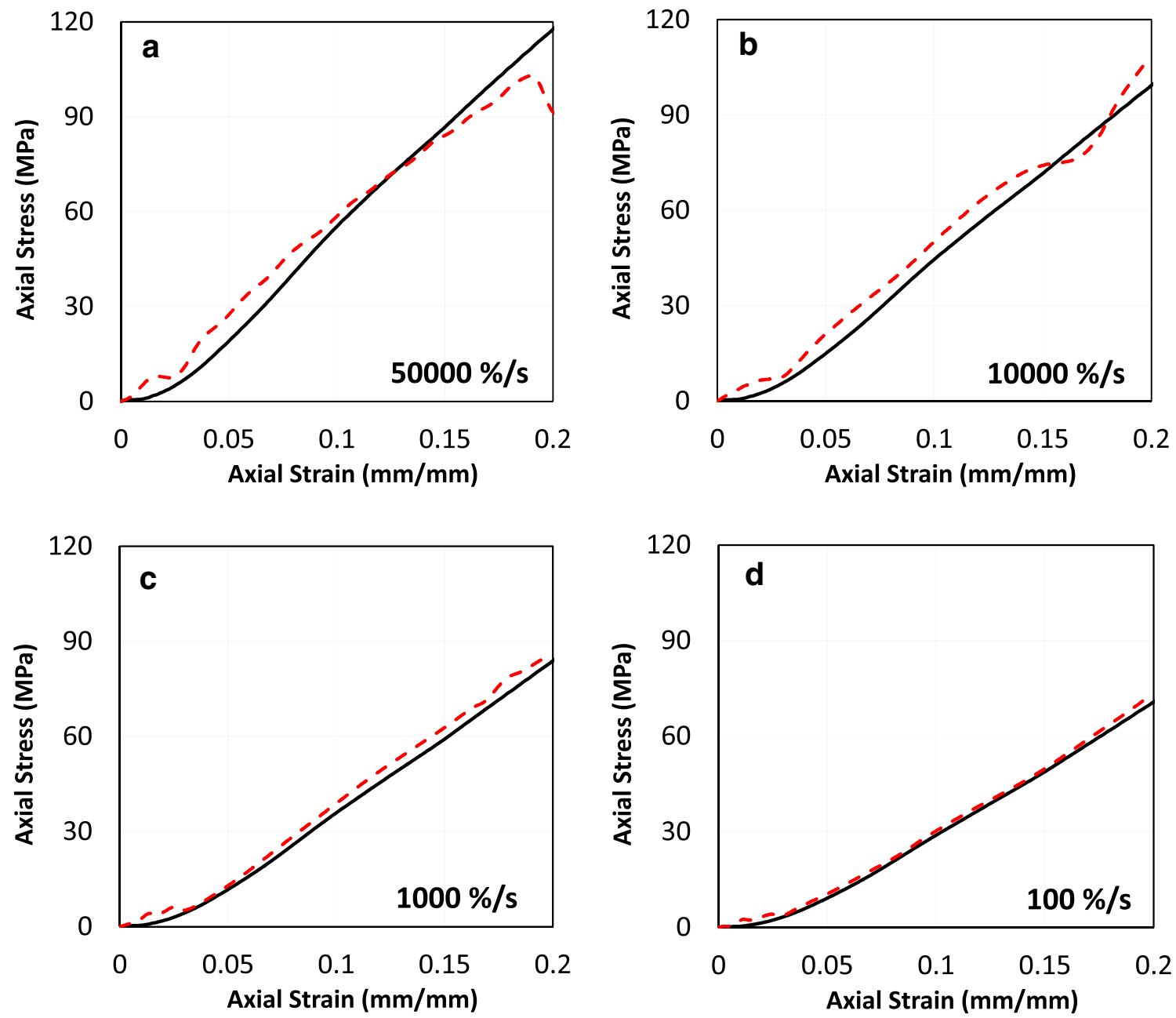

Fig. 19 HSR experimental versus predicted stress-strain curves of a 500,000\%/s, b 10,000\%/s, c $1000 \% / \mathrm{s}$, and d $100 \% / \mathrm{s}$ in coral sand (experimental data is shown in dashed lines, and predicted data in solid lines)

test time and strain rate values respectively to validate the efficacy of the obtained results, and results were deemed reliable in the investigated test range. The results show distinct measurable strain rate effects for silica and coral sands under uniaxial test conditions. This behavior varies from one sand to another and depends on several factors that have not been fully explored in this study, but include material composition. Test results indicate that generally, the stress-strain curves during the first $0.50 \%$ of strain have similar stiffness, which is attributed to the stiffness of the loading device. As the strain levels reach $10 \%$ strain an increase in stress of about $15 \%$ is observed, when strain rates vary from 0.001 to $10 \% / \mathrm{s}$.

An empirical approach, based on the equivalence of SED between tests conducted at various strain rates was developed. A model that accounted for viscoelastic-viscoplastic behavior was employed to predict stress-strain response of sand at different strain loading rates, using a reference stress-strain test conducted at a lower strain rate. The parameters of both visco-elastic and visco-plastic components were computed together by curve fitting a function $m$, which is material and strain dependent through the results of four constant engineering strain rate tests. Comparison between conventional low to intermediate strain rate uniaxial compression tests, and prediction using the SED approach indicates that SED is an appropriate methodology for extrapolating stress strain behavior to scenarios involving HSR. Thus, the proposed methodology provides a powerful approach for estimating HSR, using test conducted at slower strain rates.

Acknowledgments The authors gratefully acknowledge the support of the Defense Threat Reduction Agency Grant No: HDTRA1-10-10049 and The United States National Science Foundation Grant No: DGE 0741714.

\section{References}

1. Tatsuoaka F, Santucci de Magistris F, Hayano K, Momoya Y, Koseki J (2000) Some new aspects of time effects on the stressstrain behavior of stiff geomaterials. Keynote Lecture. The 
Geotechnics of Hard Soils-soft Rocks. In Proceedings of second international conference on hard soils and soft rocks, Naples, 1998, vol 2, pp 1285-1371

2. Reeves G, Coyle H, Hirsch T (1967) Investigation of sands subjected to dynamic loading, Report. Texas Transportation Institute

3. Farr V (1986) Loading rate effects on the one-dimensional compressibility of four partially saturated soils, Report. U.S. Army Waterways Experiment Station

4. Huy NQ, van Tol AF, Holscher P (2006) Laboratory investigation of the loading rate effects in sand, Report. Delft University of Technology

5. Gu Q, Lee FH (2002) Ground response to dynamic compaction of dry sand. Geotechnique 52(7):481-493

6. Caudle W, Pope A, McNeill R, Margason B (1968) "The feasibility of rapid soil investigations using high-speed earth-penetrating projectiles". In: Proceedings of the international symposium wave propagation \& dynamic properties of earth materials. U. New Mexico Press, pp 945-955

7. Zelikson A, Boisson JY, Leguay P, Hembise O, Bradey P (1986) Instrumented projectiles in centrifuge modeling of seabed penetration. Soil Dyn Earthq Eng 5(4):239-247

8. Omidvar M, Iskander M, Bless S (2012) Stress-strain behavior of sand at high strain rates. Int J Impact Eng 49:192-213

9. Casagrande A, Shannon WL (1948) Strength of soils under dynamic loads. Proc ASCE 74(4):591-608

10. Seed H, Lundgren R (1954) Investigation of the effect of transient loadings on the strength and deformation characteristics of saturated sands. Proc ASTM 54:1288-1306

11. Matsushita M, Tatsuoka F, Koseki J, Cazacliu B, Benedetto H, Yasin SJM (1999) Pre-failure deformation characteristics of geomaterials. In: Jamiolkowski M, Lancelotta R, Lo Presti D (eds) Time effects on the pre-peak deformation properties of sands. Balkema, Rotterdam, pp 681-689

12. Lade PV, Liggio CD Jr, Nam J (2009) Strain rate, creep, and stress drop-creep experiments on crushed coral sand. ASCE J Geotech Geoenviron Eng 135(7):941-953

13. Matsuoka S (1986) Failure of plastics. In: W. Brostow, R. Comeliussen (eds) Chapter 3. Hanser Publishers, Stuttgart, Germany, pp 24-59

14. Merry S, Bray J (1997) Time-dependent mechanical response of HDPE feomembranes. J Geotech Geoenviron Eng 123(1):57-65

15. Bozorg-Haddad A, Iskander M (2011) Comparison of accelerated compressive creep behavior of virgin HDPE using thermal and energy approaches. J Mater Eng Perform 20(7):1219-1229. doi:10.1007/s11665-010-9743-9

16. Dasari A, Misra RDK (2003) On the strain rate sensitivity of high density polyethylene and polypropylenes. Mater Sci Eng A 358(1):356-371

17. Southgate H, Deen R, Mayes J (1982) Strain energy analysis of pavement designs for heavy trucks. Kentucky Transportation Center Research Report. Paper 781

18. Lu Y, Xu K (2004) Modelling of dynamic behavior of concrete materials under blast loading. Int J Solids Struct 41(1):131-143

19. Farr J, Woods R (1988) A device for evaluating one-dimensional compressive loading rate effects. Geotech Test J 11(4):269-275
20. ASTM Standard D4253-00 (2006) Standard test methods for maximum index density and unit weight of soils using a vibratory table. ASTM International, West Conshohocken

21. ASTM Standard D4254-00-e1 (2006) Standard test methods for minimum index density and unit weight of soils and calculation of relative density. ASTM International, West Conshohocken

22. Suescun-Florez E, Omidvar M, Iskander M, Bless S (2015) Review of high strain rate testing of granular soils. Geotech Test $\mathbf{J}$ 38(4):1-26. doi:10.1520/GTJ20140267

23. McDowell G, Bolton M (1998) On the micromechanics of crushable aggregates. Geotechnique 48(5):667-679

24. Einav I (2007) Breakage mechanics - part I: theory. J Mech Phys Solids 55(6): 1274-1297

25. Farr JV (1990) One-dimensional loading-rate effects. J Geotech Eng 116(1):119-135

26. Lee KL, Seed HB, Dunlop P (1969) Effect of transient loading on the strength of sand. In: Proceedings of the 7th international conference on soil mechanics and foundation engineering. Sociedad Mexicana, Mexico City, vol. 1, pp 239-247

27. Kabir ME, Song B, Martin BE, Chen W (2010) Compressive behavior of fine sand. Report SAND2010-2289. Sandia Laboratories, Albuquerque

28. Perzyna P (1966) Fundamental problems in viscoplasticity. Adv Appl Mech 9:244-377

29. Simo JC, Ju JW (1987) Strain-and stress-based continuum damage models-I. Formulation. Int J Solids Struct 23(7):821-840

30. Simo JC, Govindjee S (1991) Non-linear B-stability and symmetry preserving return mapping algorithms for plasticity and viscoplasticity. Int J Numer Meth Eng 31(1):151-176

31. Wang Z, Hao H, Lu Y (2004) A three-phase soil model for simulating stress wave propagation due to blast loading. Int $\mathrm{J}$ Numer Anal Meth Geomech 28(1):33-56

32. Laine L, Sandvik A (2001) Derivation of mechanical properties for sand. In: Proceedings of the 4th Asia-Pacific conference on shock and impact loads on structures. CI-Premier PTE LTD, ANSYS Inc, Singapore, vol 361, p 368

33. Tong X, Tuan CY (2007) Viscoplastic cap model for soils under high strain rate loading. J Geotech Geoenviron Eng 133(2):206-214

34. Sih GC (1991) Mechanics of fracture initiation and propagation. Kluwer, Alphen aan den Rijn

35. Bozorg-Haddad A, Iskander M, Wang HL (2010) Compressive creep of virgin HDPE using equivalent strain energy density method. J Mater Civ Eng 22(12):1270-1281

36. Bozorg-Haddad A, Iskander M, Chen Y (2012) Compressive strength and creep of recycled HDPE used to manufacture polymeric piling. Constr Build Mater 26(1):505-515

37. Suleiman M, Coree B (2004) Constitutive model for HDPE material: a systematic approach. J Mater Civ Eng 16(6):511-515

38. Luo H, Lu WL, Komanduri R (2011) Effect of mass density on the compressive behavior of dry sand under confinement at high strain rates. Exp Mech 51(9):1499-1510

39. Hardin BO, Drnevich VP (1972) Shear modulus and damping in soils: measurement and parameter effects. J Soil Mech Found Div ASCE 98(6):603-624 